(c) American Dairy Science Association, 2006.

\title{
Short Communication: Disinfectant Containing a Complex of Skin Conditioners
}

\author{
L. K. Fox, ${ }^{* 1}$ C. Gradle, $†$ and A. Dee† \\ ${ }^{*}$ College of Veterinary Medicine, Washington State University, Pullman 99164 \\ tWestfalia Surge, Inc., 1880 Country Farm Dr, Naperville, IL 60563
}

\begin{abstract}
The efficacies of 2 new teat dip formulations were tested against experimental challenge by contagious mastitis pathogens Staphylococcus aureus and Streptococcus agalactiae over a 12 -wk period. Formulations contained an iodine complex ( 0.5 or $1.0 \%$ iodine) and skin conditioning agents (propylene glycol, polyvinylpyrridone, glycerine, lanolin, allantoin, and aloe). Percentage reduction (dipped vs. control mammary quarters) in new contagious mastitis pathogen intramammary infections for the 0.5 and $1.0 \%$ iodine dips was 65.4 and 84.5, respectively. Both dips were significantly effective in reducing new contagious intramammary infections. Teat skin scores and teat end scores varied over time but were virtually identical for both treated and control teats, for both treatments. Thus, both dips were effective in reducing new contagious mastitis infections without untoward effects on teat skin condition.
\end{abstract}

Key words: teat dip, contagious mastitis, skin condition

Postmilking teat asepsis with a teat dip is a common mastitis prevention practice that provides excellent control of mastitis (Hutton et al., 1990; Barkema et al., 1998). Effective teat dips must have adequate disinfectant properties and not cause any untoward effects on teat skin health because greater colonization of Staphylococcus aureus is associated with chapped compared with healthy teat skin (Fox et al., 1991). In an effort to maintain teat skin integrity, teat dip formulations are balanced with skin conditioning agents, either emollients or humectants (Pankey et al., 1984). The purpose of the current study was to determine the efficacy of control of contagious mastitis using 2 new teat dip formulations that contained both humectants (glycerine, propylene glycol, and polyvinylpyrridone), and an emollient (lanolin). Additionally, the formulation contained

Received December 16, 2005.

Accepted February 15, 2006.

${ }^{1}$ Corresponding author: Fox@wsu.edu aloe and allantoin, agents that have been reported to have skin-healing properties (MacKay and Miller, 2003).

Evaluation of 2 new teat dip formulations (375 and 393, WestfaliaSurge, Inc., Naperville, IL) was conducted according to National Mastitis Council procedures as outlined by Hogan et al. (1990, 1999), and described in more detail by Oura et al. (2002). An experimental challenge protocol as outlined by Boddie and Nickerson (1998) was used. In brief, the IMI status of all mammary quarters of cows eligible for the trial at the Washington State University Dairy Center was determined by aseptic collection and culture of milk samples collected from 3 successive samplings at 24-h intervals starting May 5, 2005, with enrollment of cows on trial on May 10. Staphylococcus aureus were identified by colony morphology, hemolytic patterns, and by the tube coagulase test; Streptococcus agalactiae were identified by hemolytic pattern, colony morphology, Christie, Atkins, Munch-Petersen (CAMP) reaction, and catalase test. Milk samples were collected from all mammary quarters weekly and cultured within $1 \mathrm{~d}$ of collection. Additional milk samples were collected as follows. Isolation of either Staph. aureus or Strep. agalactiae for the first time from a previously uninfected quarter triggered collection of another sample within $2 \mathrm{~d}$ after first isolation, and continuing daily thereafter until diagnosis could be confirmed or denied. Results of this second sample were used to help confirm an IMI; an IMI was confirmed when: 1) Staph. aureus or Strep. agalactiae was isolated from a mammary quarter with clinical mastitis; 2) 2 consecutive samples yielded $\geq 500$ $\mathrm{cfu} / \mathrm{mL}$ of the same pathogen; 3) 3 consecutive samples contained 100 to $400 \mathrm{cfu} / \mathrm{mL}$ of the same pathogen; or 4) 5 consecutive samples contained $>1 \mathrm{cfu} / \mathrm{mL}$ of the same pathogen. All mammary quarters were eligible for new IMI during the trial except those infected with organisms of the same species as the challenge organisms, and those mammary quarters that were not functional.

Test dips 375 and 393 contained 0.5 and $1.0 \%$ iodine, respectively, and were evaluated for their ability to prevent IMI by contagious pathogens. The iodine was part of a polyvinylpyrrolidone iodine complex. The skin 
Table 1. Incidence of new IMI in dipped (treated) vs. undipped (control) mammary quarters by pathogen type (Staphylococcus aureus and Streptococcus agalactiae $)^{1}$

\begin{tabular}{|c|c|c|c|c|}
\hline $\begin{array}{l}\text { Dip } \\
\text { type }\end{array}$ & Treatment & $\begin{array}{l}\text { Total } \\
\text { IMI }\end{array}$ & $\begin{array}{l}\text { Staph. } \\
\text { aureus } \\
\text { IMI }\end{array}$ & $\begin{array}{l}\text { Strep. } \\
\text { agalactiae } \\
\text { IMI }\end{array}$ \\
\hline \multirow[t]{2}{*}{ DX 375} & Treated & $9^{a}$ & 1 & 8 \\
\hline & Control & $26^{\mathrm{b}}$ & 0 & 26 \\
\hline \multirow[t]{2}{*}{ DX 393} & Treated & $2^{\mathrm{a}}$ & 1 & 1 \\
\hline & Control & $13^{b}$ & 1 & 12 \\
\hline
\end{tabular}

${ }^{a, b}$ Numbers, as measured by percentage reduction, within dip type not sharing the same superscript are significantly different $(P<0.05)$.

${ }^{1}$ For dip DX 375, 88 treated and 88 control teats were enrolled; for dip DX 393, 111 control and 110 treated teats were enrolled.

conditioning agents included glycerine, propylene glycol, lanolin, allantoin, polyvinylpyrridone, and aloe, which comprised $7 \%$ of the 375 dip and $14 \%$ of the 393 dip. Cows at Washington State University's Dairy Center $(\mathrm{n}=100)$ were systematically assigned to 2 groups. At the morning milking, Monday through Friday, all functional teats of each cow were immersed in a challenge suspension containing Staph. aureus (ATCC 29740) and Strep. agalactiae (ATCC 27956) immediately after the milking machines were removed. A right or left mammary gland half was systematically assigned to receive one of the postmilking teat dips (treated teats); the other side remained as an undipped control. Cows with odd-numbered ear tags received dip on their left mammary half, and cows with even-numbered ear tags received dip on their right mammary half. Teats receiving dip were immersed in the test

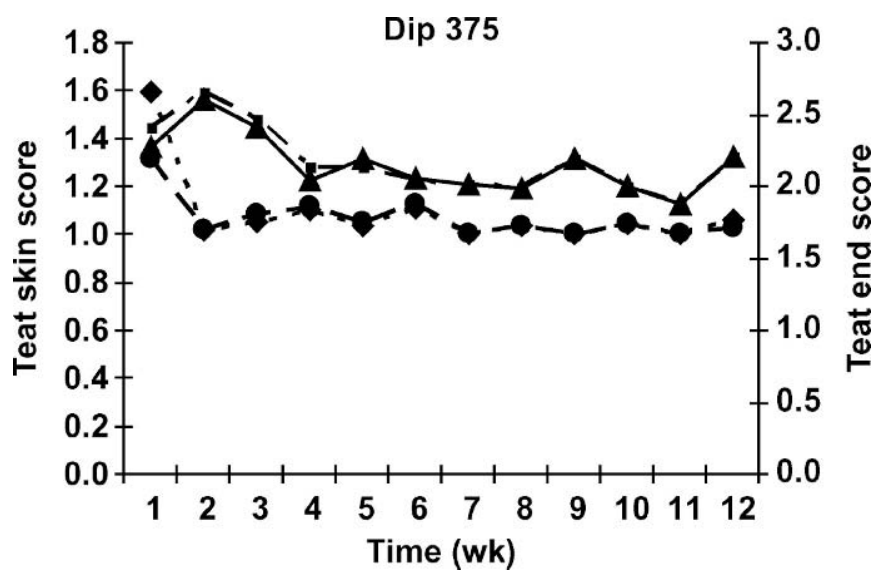

Figure 1. Teat skin and teat end scores as a function of time (wk) for dip 375. Control teat skin condition and end scores are represented by $\boldsymbol{}$ and $\boldsymbol{\Lambda}$, respectively; treatment teat skin condition and end scores are represented by and $\boldsymbol{\square}$, respectively. A score of 1 for either teat end or teat skin indicated that the epidermis had no visual damage; a score of 5 to either site reflected severely damaged epidermis.

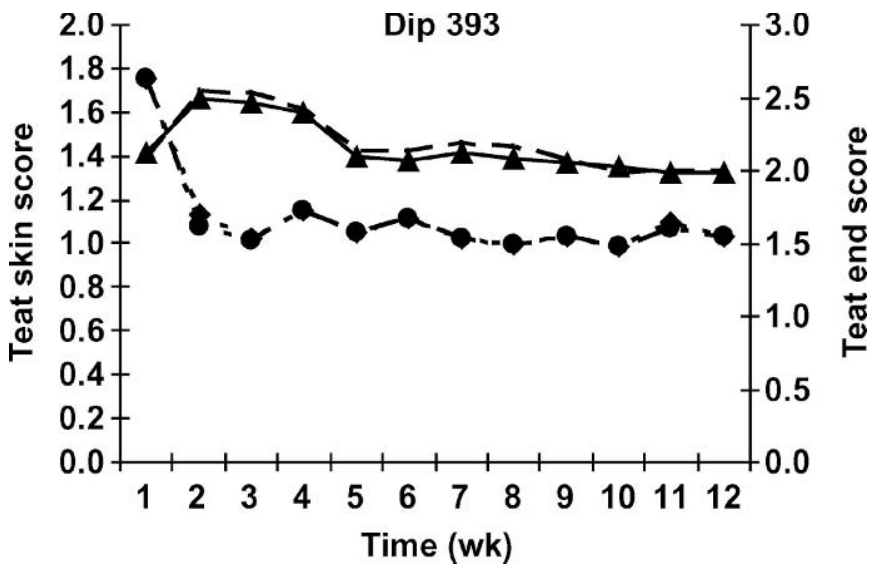

Figure 2. Teat skin and teat end scores as a function of time (wk) for dip 393. Control teat skin condition and end scores are represented by - and $\boldsymbol{\Delta}$, respectively; treatment teat skin condition and end scores are represented by $\boldsymbol{\wedge}$ and $\mathbf{\square}$, respectively. A score of 1 for either teat end or teat skin indicated that the epidermis had no visual damage; a score of 5 to either site reflected severely damaged epidermis.

germicide after both daily milkings, $7 \mathrm{~d} / \mathrm{wk}$ for a 12 -wk period. For the test of dip 375, 88 teats were included as controls and 88 were treatment; for dip 393, 111 were controls and 110 were treated.

The effectiveness of both dips was determined by contrasting the differences between the percentages of quarters becoming infected in mammary gland halves that received postmilking disinfection compared with controls. The $t$-statistic test as described by Hogan et al. (1990) was used.

Characteristics of teat skin surfaces and teat ends for both groups of cows were scored immediately before the trial, weekly during the trial, and at the conclusion of the trial, to determine possible effects of the germicidal solutions on teat skin condition. Condition scores for teat skin and teat ends were characterized according to the criteria established by Goldberg et al. (1994) by a single technician not informed as to the allocation of treatments. According to the criteria (Goldberg et al., 1994), a score of 1 to either teat end or teat skin indicated that the epidermis had no visual damage; a score of 5 to either site reflected severely damaged epidermis. To test differences in teat skin conditions between treated and control teats, a mixed model was constructed (SAS Institute, 1994). This model included week, cow, and treatment as categorical variables in a repeated measure design in which treatment was nested within cow, and week of scoring was the measure of repetition. Dependent variables, scores for teat end and teat skin condition, were regressed against the independent variables time (week), treatment (control or dipped), and time by treatment. 
The new IMI are summarized in Table 1 by treatment (dipped or control), teat dip type (375 vs. 393), and by contagious pathogen type (Staph. aureus and Strep. agalactiae) during the $12 \mathrm{wk}$ of the trial. Mammary quarters receiving the 375 dip had 9 new contagious IMI vs. 26 in corresponding control quarters. Mammary quarters receiving the 393 dip had 2 new contagious IMI vs. 13 in corresponding control quarters. The percentage reduction in new contagious IMI was 65.4 and 84.5 for treated mammary quarters vs. controls for the 375 and 393 dips, respectively. The t-statistics for the differences in total IMI with challenge organisms were 82.2 and 59.92 for dips 375 and 393, respectively. These $t$-statistics indicate significance at $P<0.001$, indicating that both dips significantly reduced new IMI to contagious pathogens as tested.

Changes in skin condition are depicted in Figures 1 and 2; it should be noted that teat end scores and teat skin scores for both control and treated teats were often indistinguishable. For both dips (375 and 393), teat end scores and teat skin scores were significantly affected by time. Teat end scores for both dip types were elevated for the first 3 to $4 \mathrm{wk}$, and decreased thereafter. Teat skin scores were only elevated during the first week, the pretreatment period, and then decreased thereafter. Thus, scores were higher at the start of the trial (early May), and decreased by mid-June. Teat skin and end condition appeared to be best in the Pacific Northwest in the summer months compared with other times of the year (Burmeister et al., 1995). Scores were not affected by treatment or treatment by time, indicating that treatment had no affect on teat skin condition and suggesting that improvement was a result of climatic seasonal changes.

Both dips significantly reduced the incidence of IMI by the challenge pathogens in aggregate. Additionally, teat skin condition, as measured by both teat end and teat skin scores, did not differ significantly between treatment groups. In fact, teat condition was virtually identical for both dipped and control teats for both treatments (Figures 1 and 2). Dipping teats in a disinfectant solution after milking may negatively affect teat skin condition compared with not dipping (Oura et al., 2002). Alternatively, use of oil-based teat dips, in which the oil acts as a skin conditioning agent (an emollient), improved teat skin condition but was associated with a significantly greater rate of contagious IMI than no- dip controls (Philpot and Pankey, 1975). Apparently, with oil-based teat dips, the oil interferes with the active ingredient (iodine), and exacerbates, rather than controls, contagious mastitis (Pankey et al., 1984). Thus, a dip with added skin conditioning agents that can maintain teat skin health and reduce contagious mastitis would have merit. The dips tested in the current study prevented contagious mastitis without untoward effects on teat skin condition.

\section{REFERENCES}

Barkema, H. W., Y. H. Schukken, T. J. G. M. Lam, M. L. Beiboer, G. Benedictus, and A. Brand. 1998. Management practices associated with low, medium, and high somatic cell counts in bulk milk. J. Dairy Sci. 81:1917-1939.

Boddie, R. L., and S. C. Nickerson. 1998. Germicidal activity of a chlorous acid-chlorine dioxide teat dip and a sodium chlorite teat dip during experimental challenge with Staphylococcus aureus and Streptococcus agalactiae. J. Dairy Sci. 81:2293-2298.

Burmeister, J. E., L. K. Fox, D. D. Hancock, C. C. Gay, J. M. Gay, S. M. Parish, and J. W. Tyler. 1995. A survey of dairy managers in the Pacific Northwest identifying premilking/postmilking teat disinfectant combinations, management practices, and climatic conditions associated with teat chapping. J. Dairy Sci. 78:2073-2082.

Fox, L. K., J. A. Nagy, J. K. Hillers, J. D. Cronrath, and D. A. Ratkowsky. 1991. Effects of postmilking teat treatment on the colonization of Staphylococcus aureus on chapped teat skin. Am. J. Vet. Res. 52:799-802.

Goldberg, J. J., P. A. Murdough, A. B. Howard, P. A. Drechsler, J. W. Pankey, G. A. Ledbetter, L. L. Day, and J. D. Day. 1994. Winter evaluation of a postmilking powdered teat dip. J. Dairy Sci. 77:748-758.

Hogan, J. S., D. M. Galton, R. J. Harmon, S. C. Nickerson, S. P. Oliver, and J. W. Pankey. 1990. Protocols for evaluating efficacy of postmilking teat dips. J. Dairy Sci. 73:2580-2585.

Hogan, J. S., R. N. Gonzalez, R. J. Harmon, S. C. Nickerson, S. P. Oliver, J. W. Pankey, and K. L. Smith. 1999. Laboratory Handbook on Bovine Mastitis. National Mastitis Council, Inc., Madison, WI.

Hutton, C. T., L. K. Fox, and D. D. Hancock. 1990. Mastitis control practices. Differences between high and low milk somatic cell counts. J. Dairy Sci. 73:1135-1143.

MacKay, D., and A. L. Miller. 2003. Nutritional support for wound healing. Altern. Med. Rev. 8:359-377.

Oura, L. Y., L. K. Fox, C. C. Warf, and G. K. Kemp. 2002. Efficacy of two acidified chlorite postmilking teat disinfectants with sodium dodecylbenzene sulfonic acid on prevention of contagious mastitis using an experimental challenge protocol. J. Dairy Sci. 85:252257.

Pankey, J. W., R. J. Eberhart, A. L. Cuming, R. D. Daggett, R. J. Farnsworth, and C. K. McDuff. 1984. Uptake on postmilking teat antisepsis. J. Dairy Sci. 67:1336-1353.

Philpot, W. N., and J. W. Pankey. 1975. Hygiene in the prevention of udder infections. II. Evaluation of oil-based teat dips. J. Dairy Sci. 58:205-208.

SAS Institute. 1994. SAS User's Guide. 6th ed. SAS Institute, Inc., Cary, NC. 